\title{
THE DETERMINATION OF THE VAPOUR PRESSURES OF SODIUM AND POTASSIUM CHLORIDES
}

\section{AUTHOR(S):}

Horiba, Shinkichi; Baba, Hideo

\section{CITATION:}

Horiba, Shinkichi ...[et al]. THE DETERMINATION OF THE VAPOUR PRESSURES OF SODIUM AND POTASSIUM CHLORIDES. 化學研究所學術報告 1929, 1

ISSUE DATE:

1929-11-30

URL:

http://hdl.handle.net/2433/74517

RIGHT: 
$\left[\begin{array}{c}\text { Reprinted from the Bulletin of the Chemical } \\ \text { Society of Japan. Vol. } 3 \quad \text { No. } 1 .\end{array}\right]$

\title{
THE DETERMINATION OF THE VAPOUR PRESSURES OF SODIUM AND POTASSIUM CHLORIDES.
}

\author{
By Shinkichi HORIBA and Hideo BABA.
}

Received December 23, 1927. Published January 28, 1928.

It was hitherto considered a passably difficult bit of technique to determine directly or statically the vapour pressure of a substance when it exerts quite a small vapour pressure at a high temperature, so that, even with alkali halides, the data of those vapour pressures given in the literature, ${ }^{(1)}$ which are not exceedingly small at above $1000^{\circ} \mathrm{C}$., were still determined only by dynamical methods. One of the present writers (S.H.) used a quartz pressure indicator for the determination of the vapour pressure of metallic arsenic ${ }^{(2)}$ in the Chemical Laboratory in Amsterdam by Prof. Smits and he has now succeeded in constructing a quartz pressure indicator of the same form, whose sensitivity is acute enough to determine some fractions of $\mathrm{mm}$. of mercury. In the present experiments, the writers. have applied this pressure indicator to the direct or statical determination of the vapour pressures of sodium and potassium chlorides.

Samples. Sodium chloride was precipitated from the saturated solution of the "natrium chloratum" of the Japanese Pharmacopoeia by gaseous hydrogen chloride, and this precipitate was dried in an air bath and subjected to a red heat for several hours and then kept in a desiccator made up of $\mathrm{P}_{2} \mathrm{O}_{5}$. In the case of potassium chloride, the purest sample of Kahlbaum's was recrystallised and dried in the same manner as with the sodium chloride.

The Pressure Indicator. The quartz pressure indicator used is represented by $\mathrm{A}$ in Fig. 1. Two glass windows were cemented exactly in the place of the pointer of the indicator, for the purpose of detecting even a minute deviation of the pointer from its zero point. Bèlow these windows, a water condenser, shown in the figure, served for the protection from heating of the cement used to attach the glass windows.

(1) Ruff and Magdan, Z. anorg. allgem. Chem., 117 (1921), 161; v. Wartenberg and Albrecht, Z. Elektrochem., 27 (1921), 568.

(2) Z. physik. Chem., 106 (1923), 295. 




Fig. 1.

Bath and Furnace. The thermostat used was a melted silver bath, $8 \mathrm{~cm}$. in depth, represented by B in Fig. 1 and it was placed in the middle of a large quartz cylinder, $7 \mathrm{~cm}$. in diameter, which had nichrome wire coiled in two layers on its out-side. As seen in the figure, this quartz cylinder stood in the middle of a large crucible, $30 \mathrm{~cm}$. in diameter, which was completely filled with asbestos fibre F. For the protection from cooling of the upper part of the silver bath as well as for the purpose of the fine adjustment of the temperature of the furnace, an earthen-ware tube, surrounded also with a coil of nichrome wire, was hung over the silver bath.

Filling of the Sample in the Indicator. To fill up the sample in the indicator, this was at first drawn out from the furnace and the sample was put into its bulb; then the indicator was evacuated by a Langmuir pump during 7 days-9 hours per day, or a total of 63 hours; during this pumping the bulb and spring were constantly heated from out-side at a temperature of about $600^{\circ} \mathrm{C}$. Then keeping the indicator at a very high vacuum by means of cooling the glass tube, connected between the vacuum pump and the indicator, with liquid air, the indicator was sealed off This procedure of the pumping is of great importance, for, in case of incomplete pumping, 
the experimental results of the pressure at a high temperature were always too high, owing to minute adsorbed gases in the sample as well as in the wall of the indicator, which were exceedingly difficult to remove completely.

The Method of the Measurement. After complete melting of the silver bath by electric heating of the furnace, the bulb of the indicator was put just in the middle of the silver bath and the vapour pressure of the salt was measured in the range of temperature between $1000^{\circ}$ and $1250^{\circ} \mathrm{C}$. by the usual method as indicated in the figure. For the determination of the temperature, two platinum platinum-rhodium thermocouples, calibrated with $\mathrm{Sb}, \mathrm{NaCl}, \mathrm{Ag}$ and $\mathrm{Cu}$, were used; one of which was just put in contact with the bulb of the indicator and the other near the spring. The temperature of the spring was kept always about 5 degrees higher than that of the sample to avoid the condensation of the salt vapour on the inside wall of the spring. For the determination of the vapour pressure below $1000^{\circ} \mathrm{C}$, the experiment was carried out on the out-side of the silver bath, it was, therefore, somowhat in an inferior condition in regard to the homogeneity of the temperature in comparison with the work at higher temperatures. In the experiments concering $\mathrm{NaCl}$, the measurements of the pressure could be carried out down to $800^{\circ} \mathrm{C}$.; but as for $\mathrm{KCl}$, not much weight could be put upon results obtained below $900^{\circ} \mathrm{C}$.

\section{The Results of the Experiments.}

TABLe 1.

Vapour Pressure of $\mathrm{NaCl}$.

$$
\frac{Q}{4.571}=8669, \quad C=5.04 .
$$

\begin{tabular}{|c|c|c|c|c|c|}
\hline$t^{\circ} \mathrm{C}$. & $\begin{array}{r}p(\mathrm{~mm} .) \\
\mathrm{Hg} \text { at } 6^{\circ} \mathrm{C} .\end{array}$ & $T \log p(\mathrm{~atm})$ & $\frac{Q}{4.571}$ & $\Delta \frac{Q}{4.571}$ & $p$ (mm.) Calc. \\
\hline 800 & 1. & -3045 & 8581 & -88 & 1.2 \\
850 & 2.5 & -2851 & 8643 & -26 & 2.7 \\
900 & 4.5 & -2635 & 8787 & +18 & 5.7 \\
950 & 8. & -2433 & 8743 & +74 & 6.8 \\
991 & 15. & -2154 & 8524 & -147 & 11.5 \\
1041 & 22.5 & -2008 & 8629 & -48 & 21.5 \\
1091 & 39.5 & -1752 & 8626 & -43 & 31.0 \\
1141 & 61.5 & -1543 & 8669 & 0 & 61.5 \\
1191 & 100 & -1291 & 8669 & 0 & 100.0 \\
1241 & 149.0 & -1071 & 8701 & +32 & 157.0 \\
\hline
\end{tabular}


Table 2.

Vapour Pressure of KCl.

$\frac{Q}{4.571}=8007, \quad C=4.697$.

\begin{tabular}{|c|c|c|c|c|c|}
\hline$t^{\circ} \mathrm{C}$. & $\begin{array}{c}p \text { (mm.) } \\
\text { Hg at } 0^{\circ} \mathrm{C} .\end{array}$ & $T \log p$ (atm.) & $\frac{Q}{4.571}$ & $\Delta \frac{Q}{4.57 \mathrm{l}}$ & $p$ (mm.) Calc. \\
\hline 700 & 1.5 & & & & \\
750 & 3. & & & & \\
800 & 4.5 & -2394 & 7904 & -93 & \\
900 & 7. & -2164 & 7905 & -92 & 5.6 \\
950 & 13. & -2101 & 7986 & -21 & 11. \\
980 & 16. & -1984 & 7964 & -43 & 19.4 \\
1000 & 21. & -1808 & 7981 & -26 & 30.5 \\
1041 & 32. & -1697 & 8012 & +5 & 42.6 \\
1071 & 41.5 & -1502 & 8007 & 0 & 89.5 \\
1111 & 62.5 & -1325 & 8010 & +3 & 0 \\
1150 & 89. & -1037 & 8007 & -11 & 211. \\
1210 & 152. & -837 & 7996 & & \\
1251 & 214.5 & & & & \\
\hline
\end{tabular}

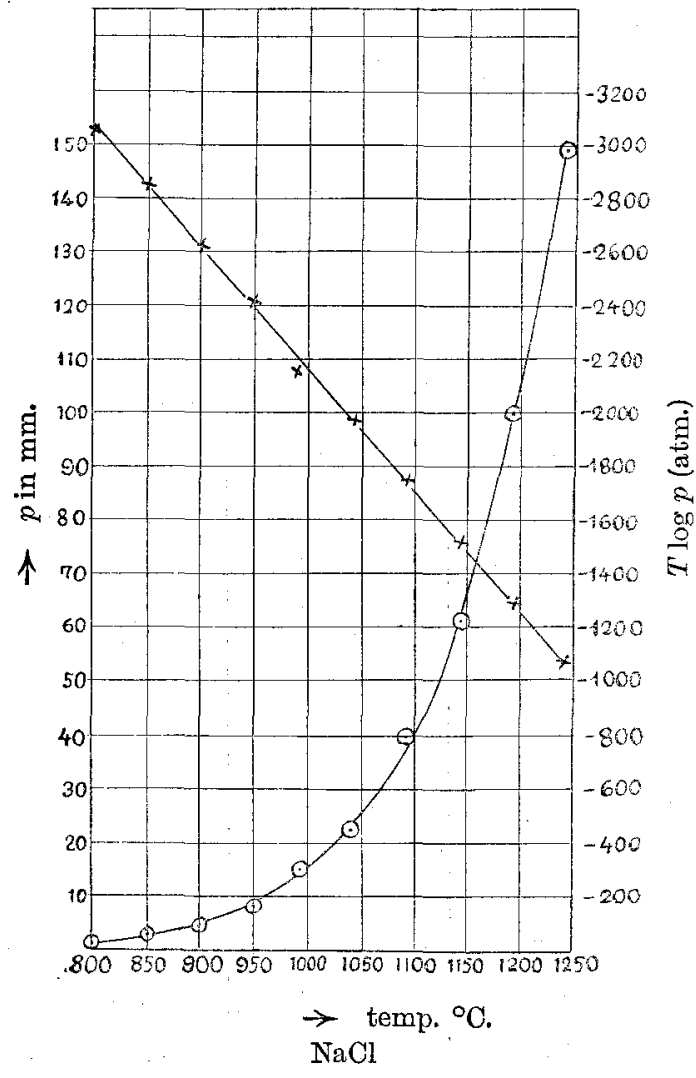

Fig 2

Applying the ClausiusClapeyron equation. $T \log p$ $=-\frac{Q}{4.57 .1}+C T, \quad$ on the above experimental results, the constants $Q$ and $C$ could be determined; from this equation the vapour pressure could be then calculated, which was shown in the last. column in the above tables.

Heats of Vapourisation and Dissociation. From Table 1, in the case of $\mathrm{NaCl}$,

$$
\frac{Q}{4.571}=8669
$$

then the heat of vapourisation of $\mathrm{NaCl}, \quad Q=39.6$ Cal.

From Table 2, in the case of $\mathrm{KCl}$,

$$
\frac{Q}{4.571}=8007
$$

then the heat of vapourisation of $\mathrm{KCl}, Q=36.6 \mathrm{Cal}$. 


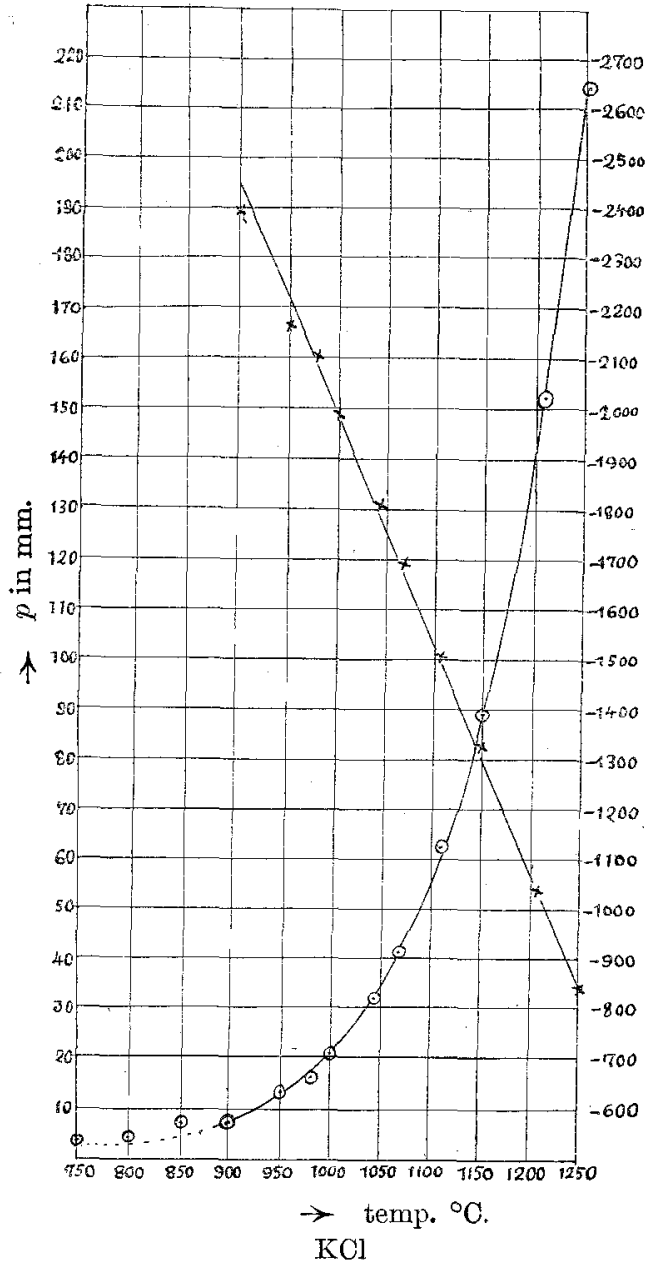

Fig. 3.

Now we shall try to find the heats of dissociation of the following reactions:

$$
\begin{aligned}
& \mathrm{NaCl}(g)=\mathrm{Na}^{+}(g)+\mathrm{Cl}^{-}(g) \\
& \mathrm{KCl}(g)=\mathrm{K}^{+}(g)+\mathrm{Cl}^{-}(g) .
\end{aligned}
$$

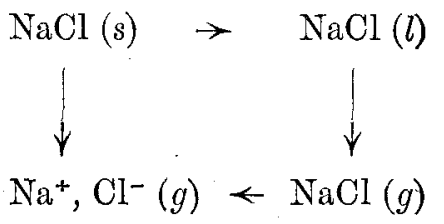

Consider a cycle represented above. Then it is easily seen that the lattice energy or heat of dissociation of solid $\mathrm{NaCl}$ into ionic gases is equal to the sum of the heat of melting, the heat of vapourisation, and the heat of dissociation of gaseous $\mathrm{NaCl}$ into gaseous ions, or

$$
U^{*}=M+Q+D
$$

and we have,

$$
U
$$

M

$\mathrm{NaCl}: \quad 181\left(\begin{array}{l}\text { Grimm u. } \\ \text { Herzfeld }\end{array}\right)^{(1)}$

$123.5\left(\begin{array}{l}\text { Plato, Sackur, } \\ \text { Lamplough }\end{array}\right)^{(2)}$

$Q$

$\mathrm{KCl}: \quad 165$ ( $\left.\begin{array}{l}\text { Grimm u. } \\ \text { Herzfeld }\end{array}\right)$

86.0 (Plato, Sackur)(2)

39.6 (The writers)

36.6 (The writers)

Then the heat of dissociation of gaseous $\mathrm{NaCl}$ :

and that of $\mathrm{KCl}$ :

$$
D=18 \mathrm{Cal} \text {. }
$$

$$
D=42 \text { Cal. }
$$

* Here in this calculation, we have neglected the temperature dependency of $U$, or the difference between the specific heats of solid and gas. Speaking more precisely, see the value $\Delta H$ on the next page.

(1) Z. Physik, 19 (1923), 149.

(2) Landolt, "Tabellen", (1923), p. 1425. 
The Dissociation Constant of $\mathrm{NaCl}$. Here a rough calculation of the dissociation constant of $\mathrm{NaCl}$ will be given only to show the order of its value. In the reaction,

$$
\mathrm{NaCl}(s)=\mathrm{Na}^{+}(g)+\mathrm{Cl}^{-}(g)
$$

the maximum work or the decrease of the free energy is

$$
A=-\Delta F=R T \ln p_{\mathrm{Na}^{+}} p_{\mathrm{Cl}^{-}}=R T \ln K .
$$

On the other hand,

$$
\Delta F=-\Delta H_{\mathfrak{p}}-T \Delta S,
$$

where $\Delta H_{p}$ is the heat of this reaction and it will be expressed as follows:

$$
\begin{aligned}
\Delta H_{p} & =U_{\mathrm{Na}_{a} \mathrm{Cl}}+2 \times \frac{5}{2} R T-\int_{0}^{T} C_{p \mathrm{NaCl}} d T^{*} \\
& =U_{\mathrm{Na} \mathrm{Cl}}+2 \times \frac{5}{2} R T-2 \int_{0}^{289} C_{v} d T-12 \times(T-298) \\
& =U_{\mathrm{Na} C 1}+2 \times \frac{5}{2} R T-2110-12 \times(T-298),
\end{aligned}
$$

where $U_{\mathrm{NaCl}}$ is the lattice energy of $\mathrm{NaCl}$ at absolute zero degree.

Assuming that an ionic gas, such as $\mathrm{Na}^{+}, \mathrm{Cl}^{-}$, behaves as a mono-atomic gas, we can easily calculate its entropy:

$$
S=C_{p} \ln T-R \ln p+S_{\lrcorner},
$$

where

$$
S_{0}=R\left[\ln \left\{\frac{(2 \pi)^{\frac{8}{2}} k_{2}^{\frac{3}{2}}}{N^{\frac{3}{2}} h^{3}}\right\}+\frac{5}{2}\right]^{* * *}+\frac{3}{2} R \ln M,
$$

or

$$
S=\frac{5}{2} R \ln T+\frac{5}{2} R-R \ln p+\frac{3}{2} R \ln M-R \times 3.66 .
$$

Then the sum of the entropies of one $\mathrm{mol}$ of $\mathrm{Na}$ and $\mathrm{Cl}$ each is

$$
\begin{aligned}
S_{\mathrm{II}}= & 5 R \ln T+5 R-2 R \ln p+\frac{3}{2} R \ln 23+\frac{3}{2} R \ln 35.46 \\
& -R \times 2 \times 3.66
\end{aligned}
$$

where we put $M_{\mathrm{Na}^{+}}=23.00 ; M_{\mathrm{Cl}^{-}}=35.46$, and the term $2 \ln p$ will be left aside when the pressure of each ion is one atmosphere.

* For our present purpose, a rough calculation for the expression $\int_{0}^{\mathrm{T}} C_{p \mathrm{NaCl}} d T$ is sufficient. We shall at first divide this integral into two parts, that is below and above the temperature $298^{\circ}$; in the part below this temperature we have $2 \int_{0}^{298} d T=2110$ cal. from Einstein's expression, putting $v=5.81 \times 10^{12}$, while in the part above, we conld put $\int_{29}^{T} C_{p \mathrm{NaOl}} d T=12$ $\times(T-298)$ approximately.

* Tolman used, in his calculation (J. Am. Chem. Soc., $43(1921), 1630)$ an experimental value -3.2 cal. deg $^{-1}$ instead of this expression, but the writers here applied the theoretical value. 
Next, the entropy of solid $\mathrm{NaCl}$ will be calculated :

$$
S_{\mathrm{NaCl}(s)}=\int_{0}^{\mathrm{T}} C_{p} d \ln T=2.3 \int_{0}^{\mathrm{T}} C_{v} \log T+2.3 \int_{0}^{\mathrm{T}}\left(C_{p}-C_{v}\right) \log T
$$

The value of it at $25^{\circ} \mathrm{C}$.(1) can be calculated by Debye's formula, and we have

$$
\frac{1}{2} S_{\mathrm{NaCl}(s)}=8.72 \mathrm{cal} . \mathrm{deg}^{-1}
$$

Neglecting the term $\left(C_{p}-C_{v}\right)$ and assuming that the specific heat of $\mathrm{NaCl}$ above $25^{\circ} \mathrm{C} .^{(2)}$ will obey Dulong-Petit's law, we have

$$
S_{\mathrm{I}}=2 \times 8.72+2 \int_{298}^{\mathrm{T}} \frac{5}{2} R d \ln T=2 \times 8.72+6 R \ln (T-298)
$$

Then

$$
\begin{aligned}
\Delta S= & S_{\mathrm{II}}-S_{\mathrm{I}} \\
= & 5 R \ln T+5 R+\frac{3}{2} R \ln 23+\frac{3}{2} R \ln 35.46 \\
& -R \times 2 \times 3.66-2 \times 8.72-6 R \ln (T-298) .
\end{aligned}
$$

Then

$$
\begin{aligned}
\Delta F= & U_{\mathrm{NaCl}}+1466-12 \times T+5 R T-5 R T \ln T-5 R T \\
& -\frac{3}{2} R T \ln 23-\frac{3}{2} R T \ln 35.46+R \times 2 \times 3.66 T \\
& +2 \times 8.72 T+6 R T \ln (T-298) .
\end{aligned}
$$

Finally we have

$$
\log K=\log \left[\mathrm{Na}^{+}\right]\left[\mathrm{Cl}^{-}\right]=-\frac{U_{\mathrm{NaCl}}+1466}{2.3 R T}+5 \log T-6 \log (T-298) .
$$

This equation will be applied in the temperature between $25^{\circ}$ and $800^{\circ} \mathrm{C}$., and at the melting point of $\mathrm{NaCl}$ or $800^{\circ} \mathrm{C}$. we have

$$
K_{1073}=10^{-39}
$$

\section{Summary.}

The vapour pressures of $\mathrm{NaCl}$ and $\mathrm{KCl}$ up to the temperature of $1250^{\circ} \mathrm{C}$. were statically determined.

The heats of vapourisation and of dissociation of these salts were calculated from the values of their vapour pressures and the order of the value of the dissociation constant of $\mathrm{NaCl}$ in gaseous state was given.

December 1927.

The Institute for Chemical Research, Kyoto.

(1) Taylor, "A treatise on physical chemistry", (1925), p. 1157.

(2) Magnus (Physik. Z., 14 (1913), 5) gave $C_{\mathrm{NaCl}}=13.33$ between $18^{\circ}$ and $763^{\circ} \mathrm{C}$. 